\title{
Overview of microRNAs as liquid biopsy biomarkers for colorectal cancer sub-type profiling and chemoresistance
}

\author{
Alfred Buhagiar', Elisa Seria ${ }^{2}$, Miriana Borg ${ }^{3}$, Joseph Borg ${ }^{4}$, Duncan Ayers ${ }^{2,5}$ \\ ${ }^{1}$ Faculty of Medicine and Surgery, University of Malta, Msida 2080, Malta. \\ ${ }^{2}$ Centre for Molecular Medicine and Biobanking, University of Malta, Msida 2080, Malta. \\ ${ }^{3}$ Faculty of medical sciences, Newcastle University, Newcastle upon Tyne NE1 7RU, UK. \\ ${ }^{4}$ Faculty of Health Sciences, University of Malta, Msida 2080, Malta. \\ ${ }^{5}$ Faculty of Biology, Medicine and Health Sciences, The University of Manchester, Manchester M13 9PL, UK.
}

Correspondence to: Dr. Duncan Ayers, Centre for Molecular Medicine and Biobanking, University of Malta, Rm31b Biomedical Bldg., Msida 2080, Malta. E-mail: Duncan.Ayers@um.edu.mt

How to cite this article: Buhagiar A, Seria E, Borg M, Borg J, Ayers D. Overview of microRNAs as liquid biopsy biomarkers for colorectal cancer sub-type profiling and chemoresistance. Cancer Drug Resist 2021;4:934-45.

https://dx.doi.org/10.20517/cdr.2021.62

Received: 30 Jun 2021 First Decision: 10 Aug 2021 Revised: 1 Sep 2021 Accepted: 24 Sep 2021 Published: 26 Oct 2021

Academic Editors: Godefridus J. Peters Copy Editor: Yue-Yue Zhang Production Editor: Yue-Yue Zhang

\begin{abstract}
Colorectal cancer (CRC) is the third most common cancer worldwide. It has also been demonstrated that over the last ten years the incidence of CRC among younger people below the age of 50 is also increasing. Screening for colorectal cancer is of utmost importance; the rationale behind screening is to target the malignancy and reduce the incidence and mortality of the disease. Diagnostic methods to screen for incidence or relapse are therefore a requisite to detect cancer as early as possible. Scientific findings demonstrate that many deaths are due to lack of screening and therefore early identification will lead to greater survivability. In colorectal cancer, diagnostic tests include liquid biopsy biomarkers. Since the discovery of microRNAs (miRNAs), many studies have demonstrated the relationship between miRNAs and the various sub-types of CRC. Several miRNAs have been identified after analysing serum or plasma samples in patients, and such miRNAs were found to be significantly dysregulated. Such findings place the possibility of miRNAs to be at the epicentre of novel diagnostic techniques for CRC identification and sub-type stratification, including other characteristics associated with CRC development such as patient prognosis. The following review serves to underline the latest findings for miRNAs with such potential for routine diagnostic employment in CRC diagnostics and treatments.
\end{abstract}


Keywords: MicroRNA, miRNA, liquid biopsy, biomarkers, colorectal cancer, cancer

\section{INTRODUCTION}

Colorectal cancer is the third most common cancer worldwide. According to a conservative estimate, over 1.8 million new cases were registered globally in 2018 , resulting in over $50 \%$ mortality and ranking second in terms of mortality ${ }^{[1]}$. In China alone, it is the fifth most prevalent disease, and since 2002 there has been an increase of $47 \%$ in its incidence ${ }^{[2]}$. It has also been demonstrated that over the last ten years the incidence of CRC among younger people (below the age of 50) is also increasing ${ }^{[3]}$. In a retrospective study, it was confirmed that CRC among the younger generation is increasing ${ }^{[4]}$. In the United States, an increase among young adults of CRC has been registered, and the exact reasons are still to be investigated, although the increased incidence may be attributed to external factors such as diet, obesity and lack of physical activity ${ }^{[5,6]}$.

A wealth of literature has been written on colorectal cancer since 1896, when Sir Jonathan Huchinson described the relationship between mucosal pigmentation and intestinal polyps, a condition that would eventually be recognised as Peutz-Jeghers syndrome ${ }^{[7]}$. In 1895, Dr. Aldred Warthin described Lynch syndrome as a hereditary disease $\mathrm{e}^{[8]}$. There are various types of colorectal cancer; adenocarcinomas account for $95 \%$ of all cases, while less common types include gastrointestinal tumours (GIST) (1\%), lymphomas (< $1 \%)$, carcinoids, Turcot syndrome, Peutz-Jeghers syndrome, familial colorectal cancer and juvenile polyposis coli. Estimates from the American Cancer Society reveal that $65 \%$ of CRC cases achieve survival after intervention over a five-year time period, and this survival rate can be extended if screening is continuous during this period ${ }^{[9]}$. Hence, success in preventing the disease long before it surfaces is of utmost importance, and detection when it is still in the early stage, with no metastases, increases the chance of survival.

\section{COLORECTAL CANCER SUB-TYPES Two major groups of CRC exist}

The non-hereditary types are classified on the location of origin of the malignancy

(1) Adenocarcinomas originate in the lining of the internal surface of the colon. They result in the growth of polyps and if left untreated will result in cancer. They are usually removed during a routine colonoscopy ${ }^{[10]}$.

(2) GISTs are rare and form in cells found in the lining of the gastrointestinal tract called interstitial cells of Cajal. GISTs are classified as sarcomas since they belong to connective tissue groups, such as those of muscle, fat, deep skin tissues, nerves, blood vessels and bones ${ }^{[11]}$.

(3) Lymphomas: the origin of the majority of lymphomas are of the non-Hodgkins b-cell type, although other sub-types have also been identified ${ }^{[12]}$ and are characterised by features based on lymphoid neoplasms, according to WHO classifications ${ }^{[1,14]}$. Such tumours originate in localities other than lymph nodes, such as the caecum, due to the high presence of lymphoid tissues ${ }^{[15]}$.

(4) Carcinoids: these tumours initiate in the hormone-producing cells of the neuroendocrine origin of the enterochromaffin type, which are distributed along the gastrointestinal tract - specifically located in the crypts of lieberkuhn. Such cases are very rare, comprising less than $1 \%$ of all colonic neoplasms ${ }^{[1,17]}$.

The hereditary types of CRC are classified as follows

(1) Turcot syndrome is a variant of Lynch syndrome. It is a very rare disease; in the United States, it can register 1-2 cases per 1 million people annually ${ }^{[18]}$. The disease manifests itself as benign growths or polyps 
lining the intestinal tract and tumours to the central nervous system. It is a familial heredity disease associated with PMS2, MLH1, APC, MSH2 and MSH6 genes ${ }^{[19]}$.

(2) Peutz-Jeghers syndrome is a disorder that is inherited through autosomal dominance and characterised by intestinal polyps in association with skin patterns with melanin deposition ${ }^{[20,21]}$. Such hamartomatous polyps increase the chance of colorectal cancer ${ }^{[22]}$, and its incidence varies from 1 in 50,000 to 1 in 200,000 births ${ }^{[23]}$.

(3) Familial colorectal cancer, also known as non-syndromic ${ }^{[24]}$, is a group characterised by dissimilar conditions in patients with unidentified hereditary disorders and other intermittent forms that accumulate over time in families.

(4) Juvenile polyposis syndrome is a condition determined by the histology of the polyps formed in the digestive tract. The genetic condition of this syndrome can be passed from one generation to another in a family ${ }^{[25]}$. Based on current research, two genes are involved in this condition: BMPR1A and SMAD4 ${ }^{[26]}$.

\section{SCREENING TECHNIQUES}

Screening for colorectal cancer is of utmost importance. The rationale behind screening is to target the malignancy and reduce incidence and mortality of the disease. Diagnostic methods to screen for incidence or relapse are therefore a requisite to detect cancer as early as possible. Scientific findings demonstrate that many deaths are due to lack of screening and therefore early identification will lead to greater survivability. Numerous organisations such as the American Cancer society and the American College of Physicians have recommended guidelines ${ }^{[27]}$ for colorectal cancer screening. Such guidelines are categorised into prevention and detection. What is certain is that most of the guidelines recommend screening to start at the age of 45$50^{[28]}$, the age where risk starts to increase. There have been significant improvements in screening techniques and tests. In colorectal cancer, diagnostic tests are divided into three broad categories: stoolbased analysis, liquid biomarkers and imaging. Evidence reveals that the use of such techniques in combination will enable the patient to improve therapeutic outcomes ${ }^{[29]}$.

In stool-based analysis, also known as faecal occult blood tests (FOBT), three varieties of tests can be employed which are based on guaiac oxidative reactions, immunochemical and DNA results. In guaiacbased analysis, faeces are tested for the presence of haemoglobin in the faeces. The test involves a chemical reaction by applying hydrogen peroxide through an oxidation reaction with guaiac acid via the haem molecule to convert it to guaiac blue ${ }^{[30]}$. The colour conversion is due to the presence of haemoglobin in the sample. Although it is affordable and non-invasive, the disadvantage is that it must be repeated at least three times, and the test can lead to false positive results due to dietary consumption by the patient before the test $^{[31]}$. In immunochemical tests, the faeces are tested using an antibody that is specific to human haemoglobin. This test is not affected by diet, has greater specificity, requires fewer stool samples, can be used both quantitatively and qualitatively and is non-invasive ${ }^{[32]}$. In DNA tests, patients with CRC have DNA fragments in their stools, which have a high integrity as a marker. Such DNA fragments which originate from the exfoliation of the intestinal wall cells will have genetic abnormalities associated with KRAS, $\mathrm{P}-53^{[33]}$ and epigenetic markers such as microsatellite instability ${ }^{[34]}$.

Imaging comes in different types and includes the following: (1) computed tomography provides either two- or three-dimensional images of the colon from magnetic resonance. Its diagnostic value is increasing with a reported sensitivity of $80.3 \%{ }^{[22]}$. To obtain results, the bowel has to be air distended, and in some cases the patient has to ingest a contrast agent. If the images reveal any polyps, a colonoscopy follow-up must be 
conducted. However, at the same time, this technique has a low risk of bowel perforation and does not require sedation ${ }^{[35]}$. (2) Double contrast barium enema is a technique where X-ray images are obtained after the patient's colon is covered by barium solution and then distended by air. Its use has been greatly reduced as novel imaging technology has become more available ${ }^{[36]}$. (3) Colon capsule endoscopy involves the swallowing of a pill-shaped camera capable of recording images as it passes through the gastrointestinal tract. It is expensive, requires uncompromising bowel preparation ${ }^{[37]}$ and has a reported sensitivity of $88 \%$ for polyps equal to or greater than $10 \mathrm{~mm}^{[38]}$. (4) Flexible sigmoidoscopy is a thin, flexible tube having a video camera at the tip which allows viewing the inside of the rectum and most of the sigmoid colon, which is the last two feet of the large intestine. Combined with FOBT tests, flexible sigmoidoscopy account for a reduction in $21 \%$ of CRC incidences and a $27 \%$ decrease in mortality ${ }^{[39]}$. The disadvantage is that it does not allow viewing of the entire colon as it is rather short, only about $60 \mathrm{~cm}$ in length. However, it does not require prolonged bowel preparation or sedation ${ }^{[40]}$. (5) Colonoscopy is considered as the gold standard and provides a complete image of the entire large colon and the distal part of the small colon. It also allows the ability to take a sample for biopsy during the same procedure ${ }^{[41]}$. The technique is expensive, requires sedation and extensive bowel preparation beforehand by the patient and there is also the risk of perforation during the procedure ${ }^{[42]}$.

Biomarkers: blood-based biomarkers are not new in their use. By definition, a biomarker is a biological molecule found in fluids or tissues that indicates the normal or abnormal conditions of the patient. Such serological biomarkers include carcinoembryonic antigen, epigenetic changes, DNA, RNA and microRNA. In cancer, gene expression alters significantly during the early stage of carcinogenesis. Studies have demonstrated that various genes are notably expressed in CRC, including spondin $-2^{[43]}$, Trail- $2_{2}^{[44]}$ and $\mathrm{BCNP} 1^{[45]}$.

Epigenetic modifications are also registered during carcinogenesis. Epigenetic changes are heritable alterations that influence certain genes but do not alter DNA sequence. Basically, such alterations occur as: (1) DNA methylation ${ }^{[46]}$, where it was elucidated that LINE-1 retrotransposon, if hypomethylated, is associated with unfavourable prognosis in CRC patients; (2) histone modifications, where deacetylation of histones affect the activity of $C D X 2$ gene ${ }^{[47]}$; and (3) changes in microRNA expression profiles, which, due to their high tissue specificity, stability and altered expression, can give a clear picture of the malignancy in terms of prognostic and diagnostic markers ${ }^{[48]}$.

\section{CLINICAL IMPORTANCE OF LIQUID BIOPSIES}

In recent years, one of the major efforts focused upon by biomarker researchers and clinicians alike involves the quest for novel biomarkers that can be evaluated within the clinical setting, utilising the least-invasive procedures as possible on the patient and concomitantly requiring non-complex and rapid analytical methodologies. However, the reliability and robustness of such novel biomarkers should not be reduced, despite being collected from the individual patient in a quick and painless manner.

Consequently, the concept and eventual emergence of the research niche concerning liquid biopsies was developed at the turn of the 21 st century. In essence, liquid biopsies are based on analytical methodologies focusing on reliable biomarkers that are present solely within human bodily fluids, including blood, urine, sweat, semen and saliva. In this manner, samples are collected without the requirement for highly invasive and discomforting tissue biopsies from the individual patient. In addition, also in part due to the ease of sample collection, such biomarkers can be utilised for diagnoses of early, asymptomatic phases for a particular disease condition. Presently, most of the established liquid biopsy analytical tests or screens focus on blood (whole, plasma or serum based) samples within the clinical settings, mainly due to blood being a 
formidable vehicle for an abundance of varying potential biomarkers (of differing origins), albeit there exists a trade-off since blood sampling can be discomforting for a small segment of the patient population due to needle-stick invasiveness of the sampling procedure.

In this respect, microRNAs (miRNAs) are highly adept for acting as liquid biopsy-based biomarkers as they can be found, apart from within cellular cytoplasmic regions, in almost all bodily fluids and within the bloodstream (as free-circulating miRNAs or transported within exosomes). In addition, the body of evidence regarding the robustness of miRNAs as reliable diagnostic and prognostic biomarkers is clearly established. Furthermore, analytical techniques for assessing miRNA biomarker-based expression profiles can be easily and rapidly performed within the clinical laboratory setting through the employment of RTqPCR techniques. The following sections serve to describe the possibilities offered by miRNAs to serve as CRC biomarkers, particularly regarding the influence of miRNAs in CRC chemoresistance properties.

\section{DYSREGULATED MIRNAS IN COLORECTAL CANCER}

miRNAs are small non-coding RNAs having 20-22 nucleotides, and they have a major role in affecting protein expression, much needed for cell differentiation, growth and development, and are involved in the regulation of cell function and gene regulation through translational repression, gene silencing and eventual decay of $\mathrm{mRNA}^{[49]}$. Since the discovery of miRNAs, many studies have demonstrated the relationship between miRNAs and the various sub-types of CRC (see Table 1). Several miRNAs have been identified after analysing serum or plasma samples in patients and were found to be significantly dysregulated.

They act as tumour inducers, an oncomiR, by targeting tumour suppressor genes and promoting oncogenesis by downregulating such tumour suppressors ${ }^{[7]}$. This aberrant expression has been acknowledged to influence signalling pathways, including WNT/ $\beta$-catenin, epidermal growth factor receptor, transforming growth factor-beta and epithelial-to-mesenchymal transition pathways ${ }^{[75]}$. Dysregulated miRNAs have been attributed to the initiation, progression and metastasis of CRC. They have also been credited for chemoresistance exhibited in various tumours including gastric, lung and breast. For example, in CRC, miR-223 in conjunction with FBXW7 pathway was demonstrated to increase chemoresistance to doxorubicin ${ }^{[76]}$. They also cause resistance to radiotherapy, as demonstrated by miR-630, which triggers a protein kinase TP53RK that causes cancer cells to become resistant. In addition, miR-62 confers resistance to radiotherapy by activating the apoptosis gene in cancer cells $\mathrm{s}^{[77]}$.

By no means is this list exhaustive; a search on PubMed has identified comprehensive reports listing many dysregulated miRNAs ${ }^{[78-80]}$. Meanwhile, in the CRC hereditary types, this research niche is still in its infancy and lacks any identifiable dysregulated miRNAs, and consequently scientific literature on this research theme is very limited.

\section{MICRORNAS AS BIOMARKERS IN COLORECTAL CANCER}

The use of circulating miRNAs as diagnostic biomarkers is very promising. Studies have persistently demonstrated that miRNAs have a particular signature for every cancer sub-type such as breast, prostate, lung and colorectal. They are very stable in the body and have been identified in saliva, urine, plasma, serum, tears and breast milk ${ }^{[81]}$. Their stability is attributed to their packaging in micro-vesicles and exosomes and because they are bound to the argonaute proteins ${ }^{[82]}$, which protect them against degradation.

In a meta-analysis literature review of 34 scientific papers, it was elucidated that tests on serum or plasma gave a solid result of $76 \%$ sensitivity and specificity in terms of a single dysregulated miRNA signature. In all of these studies, 28 miRNAs were identified as potential biomarkers. These results demonstrate the 
Table 1. Dysregulated miRNAs in CRC

\begin{tabular}{|c|c|c|c|}
\hline \multirow{2}{*}{ Condition } & \multicolumn{2}{|c|}{ Dysregulated miRNAs } & \multirow{2}{*}{ - Ref. } \\
\hline & Upregulated & Downregulated & \\
\hline \multirow[t]{3}{*}{ Carcinoids } & miR-183, miR-488, miR-19a, miR-19b & miR-133a, miR-145, miR-146, miR-222, miR-10b & {$[50]$} \\
\hline & miR-885-5p & & [51] \\
\hline & miR-96, miR-182, miR-183, miR-196a miR-200a & miR-31, miR-129-5p, miR-133a, miR-215 & [52] \\
\hline \multirow[t]{3}{*}{ GIST } & miR-494 & $\begin{array}{l}\operatorname{miR}-218 \\
\operatorname{miR}-21\end{array}$ & $\begin{array}{l}{[53]} \\
{[54]} \\
{[55]}\end{array}$ \\
\hline & & $\begin{array}{l}\text { miR-148b-3p } \\
\text { miR-186 } \\
\text { miR-221, miR-222 } \\
\text { miR-133b }\end{array}$ & $\begin{array}{l}{[56]} \\
{[57]} \\
{[58]} \\
{[59]}\end{array}$ \\
\hline & & $\begin{array}{l}\operatorname{miR}-137 \\
\operatorname{miR}-518 a-5 p \\
\operatorname{miR}-152\end{array}$ & $\begin{array}{l}{[60]} \\
{[61]} \\
{[62]}\end{array}$ \\
\hline \multirow[t]{5}{*}{ Adenocarcinoma } & $\begin{array}{l}\text { miR-17, miR-92a, miR-20a, miR-19b, miR-18a, miR-21 } \\
\text { miR-196b }\end{array}$ & miR-145 & [63] \\
\hline & & miR-4299 & [64] \\
\hline & $\begin{array}{l}\text { miR-141, miR-19a, miR-20a, miR-19b-1, miR-19b-2, miR-16, miR-590, } \\
\text { miR-335 }\end{array}$ & & {$[65]$} \\
\hline & $\begin{array}{l}\operatorname{miR}-182 \\
\operatorname{miR}-135 b\end{array}$ & & $\begin{array}{l}{[66]} \\
{[67]}\end{array}$ \\
\hline & miR-503, miR-4417, miR-18a, miR-431, miR-1246, miR-18b & $\begin{array}{l}\operatorname{miR}-375, \operatorname{miR}-378, \text { miR-139-5p, miR-133a, miR- } \\
422 a\end{array}$ & [68] \\
\hline \multirow[t]{2}{*}{ Lymphomas } & $\begin{array}{l}\operatorname{miR}-21 \\
\text { miR-338-5p } \\
\text { miR-155-5p, miR-200c-3p, miR-130a-3p, mir125b-5p, miR-130a }\end{array}$ & $\begin{array}{l}\text { miR-451 } \\
\text { miR-451a, miR-145-5p }\end{array}$ & $\begin{array}{l}{[69]} \\
{[70]} \\
{[71]}\end{array}$ \\
\hline & miR-494, miR-21 & $\operatorname{miR}-28$ & $\begin{array}{l}{[72]} \\
{[73]}\end{array}$ \\
\hline
\end{tabular}

capability of miRNA to be used as a diagnostic and prognostic tool for the detection of CRC $(\text { see Figure } 1)^{[83]}$.

The use of miRNA in liquid biopsies is very advantageous and promising. Its principal advantage is the fact that tests are less invasive than colonoscopy, which despite being the gold standard tends to be discomforting. This minimal invasiveness in biopsy allows a wide-ranging analysis of protein levels, tumour stage, treatment effectiveness ${ }^{[84]}$ and chemoresistance - all associated with the tumour in question. The idea of using a panel of miRNAs as a diagnostic tool has gained substantive ground. A literature review demonstrated that a combination of several miRNAs ${ }^{[85]}$ can have a sensitivity of $84.7 \%$ and a specificity of 98.7\% as compared to other established biomarkers. In gastric cancer, a similar study demonstrated that a panel of six miRNA (combining miR-18a, miR-19a, miR-21, miR-92a, miR-199a and miR-421) is very ${ }^{[86]}$ effective as a diagnostic assessment.

Circulating miRNAs are very effective biomarkers to indicate different sub-types of cancer; they can also be used to monitor tumour metastasis and progression, indicate sensitivity to clinical treatment, have a high prognostic value in the disease and present a high sensitivity ${ }^{[8]}$. Their profiles also change at different stages of the malignancy, as significantly elucidated in a study, which demonstrated that the miRNA profile changed at every stage of CRC formation ${ }^{[88]}$. Several miRNA panels have been validated as biomarkers for CRC, as indicated in Table 2. 
Table 2. miRNA profiles in CRC

\begin{tabular}{|c|c|c|}
\hline miRNA panel & Biomarker viable use & Ref. \\
\hline miR-23a-3p, miR-27a-3p, miR-142-5p, miR-376c-3p & Diagnostic and prognostic & [89] \\
\hline miR-15b, miR-215, miR-145, miR-192, let-7g & Prognostic & {$[90]$} \\
\hline Let-7a, miR-1229, miR-1246, miR-150, miR-21, miR-223, mir23a & Diagnostic & [91] \\
\hline $\begin{array}{l}\text { miR-143-5p, miR-27a-3p, miR-31-5p, miR-181a-5p, miR-30b-5p, miR-30d-5p, miR-146a-5p, miR-23a-3p, } \\
\text { miR-150-5p, miR-210-3p, miR-25-3p, miR-196a-5p, miR-148a-3p, miR-222-3p, miR-30c-5p and miR-223- } \\
\text { 3p }\end{array}$ & Prognostic (stage II and III) & {$[92]$} \\
\hline Let-7i, miR-10b, miR-30b & Prognostic (high risk stage II) & [93] \\
\hline miR-5010-3p, miR-5100, miR-656-3p, miR-671-3p & Prognostic (stage II) & {$[94]$} \\
\hline miR-19a-3p, miR-21-5p, miR-425-5p & Diagnostic & {$[95]$} \\
\hline miR-103a-3p, miR-127-3p, miR-151a-5p, miR-17-5p, miR-181a-5p, miR-18a-5p, miR-18b-5p & Diagnostic & {$[96]$} \\
\hline $\operatorname{miR} 21$, miR 25, miR 18a, miR 22 & Diagnostic & [97] \\
\hline miR-301a, miR-23a & Diagnostic & {$[98]$} \\
\hline miR-1290, miR-320d & Diagnostic & [99] \\
\hline miR-20a, miR-486 & Diagnostic & {$[100]$} \\
\hline miR-223, miR-92a & Diagnostic & {$[101]$} \\
\hline
\end{tabular}

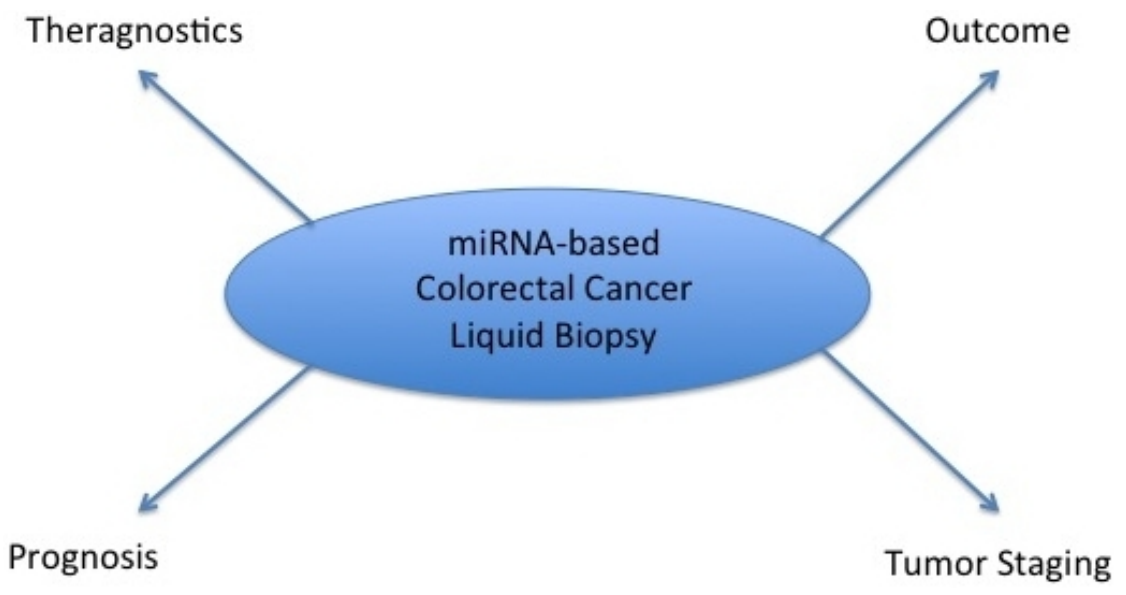

Figure 1. Outline of miRNA-based CRC biomarker potential clinical application.

The demonstrated stability in liquid biopsies with a high degree of specificity and sensitivity indicates their effectiveness as a non-invasive and low-cost test; however, they do come with limitations. One of the problems is the standardisation of tests and origin of samples. In one study, it was identified that miRNAs in arterial plasma were higher in concentration than in venous plasma ${ }^{[102]}$. It was also discovered that a panel of miRNAs was found to be significantly lower in peripheral vein and tumour tissue than in mesenteric veins in colorectal cancer.

This suggests that the panel signature is more complete in the tissue rather than in the veins. This highlights the problems encountered in sampling, which should be carefully considered before doing the tests ${ }^{[103]}$. Another factor is the difficulty of using single miRNA to distinguish between malignant and benign tumours. miR-21-5p cannot distinguish benign polyps from carcinoma in CRC patients ${ }^{[104]}$.

\section{MIRNA BIOMARKERS FOR CRC CHEMORESISTANCE}

Non-coding RNAs, including the miRNA family, have undoubtedly proven to be of ubiquitous importance across all physiological realms, including CRC chemoresistance ${ }^{[105]}$. 
The study conducted by Sasaki et al. ${ }^{[106]}$ just recently highlighted the importance of plasma miR-33a-5p to act as an effective biomarker for foresight on metastatic CRC chemotherapeutic success, focusing specifically on the typical first-line treatment combination of chemotherapeutic drugs, namely fluoropyrimidine + oxaliplatin + bevacizumab. The results of this study reveal that non-responders to CRC chemotherapeutic cycles had upregulated miR-33a-5p, indicating that patients with downregulated plasma levels for this miRNA would be more likely to respond to CRC chemotherapy ${ }^{[106]}$.

Another study conducted earlier in 2021 by Li et al. ${ }^{[107]}$ demonstrated that miR-490-3p has the capacity to thwart migration properties and chemoresistance traits (against cisplatin and fluorouracil) in CRC cells, through controlling TNKS2. Following CRC cell line-based miRNA functional analysis studies, miR-430-3p was found to be downregulated in CRC cells, and it was negatively associated with migrative properties in $\mathrm{CRC}$ and the corresponding cellular invasiveness ${ }^{[107]}$.

Furthermore, a study conducted earlier in 2021 by Mou et al. ${ }^{[108]}$ also revealed that miR-1254 has regulatory influences on oxaliplatin resistance within human CRC cell lines.

\section{CONCLUSION}

Other factors might influence the true profile of miRNAs, including gender, age, ethnicity and disease history. Therefore, additional studies are of paramount importance to validate the efficacy of using circulating miRNAs as biomarkers. Results from larger cohorts could identify reliable data and increase their potential as a non-invasive biomarker, to serve as an important clinical application in early diagnosis and to provide prognostic value in CRC.

\section{DECLARATIONS}

Authors' contributions

Contributed equally to the development of this article: Buhagiar A, Seria E, Borg M, Borg J, Ayers D

\section{Availability of data and materials}

Not applicable.

\section{Financial support and sponsorship}

None.

\section{Conflicts of interest}

All authors declared that there are no conflicts of interest.

\section{Ethical approval and consent to participate}

Not applicable.

\section{Consent for publication}

Not applicable.

\section{Copyright}

(c) The Author(s) 2021. 


\section{REFERENCES}

1. Bray F, Ferlay J, Soerjomataram I, Siegel RL, Torre LA, Jemal A. Global cancer statistics 2018: GLOBOCAN estimates of incidence and mortality worldwide for 36 cancers in 185 countries. CA Cancer J Clin 2018;68:394-424. DOI PubMed

2. Wang YN, Chen ZH, Chen WC. Novel circulating microRNAs expression profile in colon cancer: a pilot study. Eur J Med Res 2017;22:51. DOI PubMed PMC

3. Chen B, Xia Z, Deng YN, et al. Emerging microRNA biomarkers for colorectal cancer diagnosis and prognosis. Open Biol 2019;9:180212. DOI PubMed PMC

4. Campos FGCM, Figueiredo MN, Monteiro M, Nahas SC, Cecconello I. Incidence of colorectal cancer in young patients. Rev Col Bras Cir 2017;44:208-15. DOI PubMed

5. Yang J, Yu J. The association of diet, gut microbiota and colorectal cancer: what we eat may imply what we get. Protein Cell 2018;9:474-87. DOI PubMed PMC

6. Bailey CE, Hu CY, You YN, et al. Increasing disparities in the age-related incidences of colon and rectal cancers in the United States, 1975-2010. JAMA Surg 2015;150:17-22. DOI PubMed PMC

7. Campos FG, Figueiredo MN, Martinez CA. Colorectal cancer risk in hamartomatous polyposis syndromes. World J Gastrointest Surg 2015;7:25-32. DOI PubMed PMC

8. Schlussel AT, Gagliano RA Jr, Seto-Donlon S, et al. The evolution of colorectal cancer genetics-Part 1: from discovery to practice. $J$ Gastrointest Oncol 2014;5:326-35. DOI PubMed PMC

9. Simard J, Kamath S, Kircher S. Survivorship guidance for patients with colorectal cancer. Curr Treat Options Oncol 2019;20:38. DOI PubMed

10. Fleming M, Ravula S, Tatishchev SF, Wang HL. Colorectal carcinoma: pathologic aspects. J Gastrointest Oncol 2012;3:153-73. DOI PubMed PMC

11. Dimitrakopoulou-Strauss A, Ronellenfitsch U, Cheng C, et al. Imaging therapy response of gastrointestinal stromal tumors (GIST) with FDG PET, CT and MRI: a systematic review. Clin Transl Imaging 2017;5:183-97. DOI PubMed PMC

12. Tevlin R, Larkin JO, Hyland JM, O'Connell PR, Winter DC. Primary colorectal lymphoma - a single centre experience. Surgeon 2015;13:151-5. DOI PubMed

13. Beaton C, Davies M, Beynon J. The management of primary small bowel and colon lymphoma--a review. Int J Colorectal Dis 2012;27:555-63. DOI PubMed

14. Gay ND, Chen A, Okada CY. Colorectal lymphoma: a review. Clin Colon Rectal Surg 2018;31:309-16. DOI PubMed PMC

15. Wong MT, Eu KW. Primary colorectal lymphomas. Colorectal Dis 2006;8:586-91. DOI PubMed

16. Salyers WJ, Vega KJ, Munoz JC, Trotman BW, Tanev SS. Neuroendocrine tumors of the gastrointestinal tract: case reports and literature review. World J Gastrointest Oncol 2014;6:301-10. DOI PubMed PMC

17. Degnan AJ, Tocchio S, Kurtom W, Tadros SS. Pediatric neuroendocrine carcinoid tumors: management, pathology, and imaging findings in a pediatric referral center. Pediatr Blood Cancer 2017;64:e26477. DOI PubMed

18. Busbait S, Al-babtain A, Tawfeeq Y, Aljehani Y, Al-buainain H. Turcot's syndrome presenting as an acute abdomen. J Pediatr Surg Case Rep 2019;40:17-9. DOI

19. Lebrun C, Olschwang S, Jeannin S, Vandenbos F, Sobol H, Frenay M. Turcot syndrome confirmed with molecular analysis. Eur J Neurol 2007;14:470-2. DOI PubMed

20. Daniell J, Plazzer JP, Perera A, Macrae F. An exploration of genotype-phenotype link between Peutz-Jeghers syndrome and STK11: a review. Fam Cancer 2018;17:421-7. DOI PubMed

21. Tan H, Mei L, Huang Y, et al. Three novel mutations of STK11 gene in Chinese patients with Peutz-Jeghers syndrome. BMC Med Genet 2016;17:77. DOI PubMed PMC

22. Chen HY, Jin XW, Li BR, et al. Cancer risk in patients with Peutz-Jeghers syndrome: a retrospective cohort study of 336 cases. Tumour Biol 2017;39:1010428317705131. DOI PubMed

23. Qiu Y, Xuan T, Yin M, et al. Clinical characteristics and genetic analysis of gene mutations in a Chinese pedigree with Peutz-Jeghers syndrome. Clin Case Rep 2019;7:735-9. DOI PubMed PMC

24. Armelao F, de Pretis G. Familial colorectal cancer: a review. World J Gastroenterol 2014;20:9292-8. DOI PubMed PMC

25. Rosty C. The role of the surgical pathologist in the diagnosis of gastrointestinal polyposis syndromes. Adv Anat Pathol 2018;25:1-13. DOI PubMed

26. Jaoude JB, Hallit R, Rassy EE, Abboud B. The role of prophylactic gastrectomy in patients with juvenile polyposis syndrome. Clin Res Hepatol Gastroenterol 2019;43:e42-3. DOI PubMed

27. Sur D, Colceriu M, Sur G, Floca E, Dascal L, Irimie A. Colorectal cancer: evolution of screening strategies. Med Pharm Rep 2019;92:21-4. DOI PubMed PMC

28. Wender RC, Brawley OW, Fedewa SA, Gansler T, Smith RA. A blueprint for cancer screening and early detection: advancing screening's contribution to cancer control. CA Cancer J Clin 2019;69:50-79. DOI PubMed

29. Hadjipetrou A, Anyfantakis D, Galanakis CG, Kastanakis M, Kastanakis S. Colorectal cancer, screening and primary care: a mini literature review. World J Gastroenterol 2017;23:6049-58. DOI PubMed PMC

30. Li JN, Yuan SY. Fecal occult blood test in colorectal cancer screening. J Dig Dis 2019;20:62-4. DOI PubMed

31. Kościelniak-Merak B, Radosavljević B, Zając A, Tomasik PJ. Faecal occult blood point-of-care tests. J Gastrointest Cancer 2018;49:402-5. DOI PubMed PMC

32. Berry E, Miller S, Koch M, Balasubramanian B, Argenbright K, Gupta S. Lower abnormal fecal immunochemical test cut-off values 
improve detection of colorectal cancer in system-level screens. Clin Gastroenterol Hepatol 2020;18:647-53. DOI PubMed PMC

33. Dollinger MM, Behl S, Fleig WE. Early Detection of colorectal cancer: a multi-center pre-clinical case cohort study for validation of a combined DNA stool test. Clin Lab 2018;64:1719-30. DOI PubMed

34. Vacante M, Borzì AM, Basile F, Biondi A. Biomarkers in colorectal cancer: current clinical utility and future perspectives. World $J$ Clin Cases 2018;6:869-81. DOI PubMed PMC

35. Leung WC, Foo DC, Chan TT, et al. Alternatives to colonoscopy for population-wide colorectal cancer screening. Hong Kong Med J 2016;22:70-7. DOI PubMed

36. El Zoghbi M, Cummings LC. New era of colorectal cancer screening. World J Gastrointest Endosc 2016;8:252-8. DOI PubMed PMC

37. Kroijer R, Kobaek-Larsen M, Qvist N, Knudsen T, Baatrup G. Colon capsule endoscopy for colonic surveillance. Colorectal Dis 2019;21:532-7. DOI PubMed

38. Milluzzo SM, Bizzotto A, Cesaro P, Spada C. Colon capsule endoscopy and its effectiveness in the diagnosis and management of colorectal neoplastic lesions. Expert Rev Anticancer Ther 2019;19:71-80. DOI PubMed

39. Miller EA, Pinsky PF, Schoen RE, Prorok PC, Church TR. Effect of flexible sigmoidoscopy screening on colorectal cancer incidence and mortality: long-term follow-up of the randomised US PLCO cancer screening trial. Lancet Gastroenterol Hepatol 2019;4:101-10. DOI PubMed PMC

40. Segev L, Kalady MF, Church JM. Left-sided dominance of early-onset colorectal cancers: a rationale for screening flexible sigmoidoscopy in the young. Dis Colon Rectum 2018;61:897-902. DOI PubMed

41. Quero G, Galiandro F, Hassan C, et al. Colonoscopy quality assessment and accuracy: analysis of the influencing factors and surgical sequelae on 216 colonoscopies. Eur Rev Med Pharmacol Sci 2019;23:2532-8. DOI PubMed

42. Hernández G, Gimeno-García AZ, Quintero E. Strategies to optimise the quality of bowel cleansing. Gastroenterol Hepatol 2019;42:326-38. DOI PubMed

43. Zhang Q, Wang XQ, Wang J, et al. Upregulation of spondin-2 predicts poor survival of colorectal carcinoma patients. Oncotarget 2015;6:15095-110. DOI PubMed PMC

44. Nahacka Z, Svadlenka J, Peterka M, et al. TRAIL induces apoptosis but not necroptosis in colorectal and pancreatic cancer cells preferentially via the TRAIL-R2/DR5 receptor. Biochim Biophys Acta Mol Cell Res 2018;1865:522-31. DOI PubMed

45. Mehta RS, Chong DQ, Song M, et al. Association between plasma levels of macrophage inhibitory cytokine-1 before diagnosis of colorectal cancer and mortality. Gastroenterology 2015;149:614-22. DOI PubMed PMC

46. Lam K, Pan K, Linnekamp JF, Medema JP, Kandimalla R. DNA methylation based biomarkers in colorectal cancer: a systematic review. Biochim Biophys Acta 2016;1866:106-20. DOI PubMed

47. Graule J, Uth K, Fischer E, et al. CDX2 in colorectal cancer is an independent prognostic factor and regulated by promoter methylation and histone deacetylation in tumors of the serrated pathway. Clin Epigenetics 2018;10:120. DOI PubMed PMC

48. Ren A, Dong Y, Tsoi H, Yu J. Detection of miRNA as non-invasive biomarkers of colorectal cancer. Int J Mol Sci 2015;16:2810-23. DOI PubMed PMC

49. Iwakawa HO, Tomari Y. The functions of microRNAs: mRNA decay and translational repression. Trends Cell Biol 2015;25:651-65. DOI PubMed

50. Ruebel K, Leontovich AA, Stilling GA, et al. MicroRNA expression in ileal carcinoid tumors: downregulation of microRNA-133a with tumor progression. Mod Pathol 2010;23:367-75. DOI PubMed PMC

51. Mitsuhashi K, Yamamoto I, Kurihara H, et al. Analysis of the molecular features of rectal carcinoid tumors to identify new biomarkers that predict biological malignancy. Oncotarget 2015;6:22114-25. DOI PubMed PMC

52. Li SC, Essaghir A, Martijn C, et al. Global microRNA profiling of well-differentiated small intestinal neuroendocrine tumors. Mod Pathol 2013;26:685-96. DOI PubMed PMC

53. Fan R, Zhong J, Zheng S, et al. microRNA-218 increase the sensitivity of gastrointestinal stromal tumor to imatinib through PI3K/AKT pathway. Clin Exp Med 2015;15:137-44. DOI PubMed

54. Cao CL, Niu HJ, Kang SP, Cong CL, Kang SR. MiRNA-21 sensitizes gastrointestinal stromal tumors (GISTs) cells to imatinib via targeting B-cell lymphoma 2 (Bcl-2). Eur Rev Med Pharmacol Sci 2016;20:3574-81. PubMed

55. Kim WK, Park M, Kim YK, et al. MicroRNA-494 downregulates KIT and inhibits gastrointestinal stromal tumor cell proliferation. Clin Cancer Res 2011;17:7584-94. DOI PubMed

56. Wang Y, Li J, Kuang D, et al. miR-148b-3p functions as a tumor suppressor in GISTs by directly targeting KIT. Cell Commun Signal 2018;16:16. DOI PubMed PMC

57. Niinuma T, Kai M, Kitajima H, et al. Downregulation of miR-186 is associated with metastatic recurrence of gastrointestinal stromal tumors. Oncol Lett 2017;14:5703-10. DOI PubMed PMC

58. Ihle MA, Trautmann M, Kuenstlinger H, et al. miRNA-221 and miRNA-222 induce apoptosis via the KIT/AKT signalling pathway in gastrointestinal stromal tumours. Mol Oncol 2015;9:1421-33. DOI PubMed PMC

59. Yamamoto H, Kohashi K, Fujita A, Oda Y. Fascin-1 overexpression and miR-133b downregulation in the progression of gastrointestinal stromal tumor. Mod Pathol 2013;26:563-71. DOI PubMed

60. Liu S, Cui J, Liao G, et al. MiR-137 regulates epithelial-mesenchymal transition in gastrointestinal stromal tumor. Tumour Biol 2014;35:9131-8. DOI PubMed

61. Shi Y, Gao X, Hu Q, et al. PIK3C2A is a gene-specific target of microRNA-518a-5p in imatinib mesylate-resistant gastrointestinal stromal tumor. Lab Invest 2016;96:652-60. DOI PubMed

62. Lu HJ, Yan J, Jin PY, et al. MicroRNA-152 inhibits tumor cell growth while inducing apoptosis via the transcriptional repression of 
cathepsin L in gastrointestinal stromal tumor. Cancer Biomark 2018;21:711-22. DOI PubMed

63. Knudsen KN, Nielsen BS, Lindebjerg J, Hansen TF, Holst R, Sørensen FB. microRNA-17 is the most up-regulated member of the miR-17-92 cluster during early colon cancer evolution. PLoS One 2015;10:e0140503. DOI PubMed PMC

64. Hu J, Xu Y, Cai S. Specific microRNAs as novel biomarkers for combination chemotherapy resistance detection of colon adenocarcinoma. Eur J Med Res 2015;20:95. DOI PubMed PMC

65. Wang JY, Wang CL, Wang XM, Liu FJ. Comprehensive analysis of MicroRNA/MRNA signature in colon adenocarcinoma. Eur Rev Med Pharmacol Sci 2017;21:2114-29. PubMed

66. Perilli L, Vicentini C, Agostini M, et al. Circulating miR-182 is a biomarker of colorectal adenocarcinoma progression. Oncotarget 2014;5:6611-9. DOI PubMed PMC

67. Aslam MI, Hussein S, West K, Singh B, Jameson JS, Pringle JH. MicroRNAs associated with initiation and progression of colonic polyp: a feasibility study. Int J Surg 2015;13:272-9. DOI PubMed

68. Nagy ZB, Wichmann B, Kalmár A, et al. Colorectal adenoma and carcinoma specific miRNA profiles in biopsy and their expression in plasma specimens. Clin Epigenetics 2017;9:22. DOI PubMed PMC

69. Sun CM, Luan CF. Overexpression of microRNA-21 in peripheral blood mononuclear cells of patients with B-cell non-Hodgkin's lymphoma is associated with disease stage and treatment outcome. Eur Rev Med Pharmacol Sci 2015;19:3397-402. PubMed

70. Takei Y, Ohnishi N, Kisaka M, Mihara K. Determination of abnormally expressed microRNAs in bone marrow smears from patients with follicular lymphomas. Springerplus 2014;3:288. DOI PubMed PMC

71. Yuan WX, Gui YX, Na WN, Chao J, Yang X. Circulating microRNA-125b and microRNA-130a expression profiles predict chemoresistance to R-CHOP in diffuse large B-cell lymphoma patients. Oncol Lett 2016;11:423-32. DOI PubMed PMC

72. Cui Q, Vari F, Cristino AS, et al. Circulating cell-free miR-494 and miR-21 are disease response biomarkers associated with interimpositron emission tomography response in patients with diffuse large B-cell lymphoma. Oncotarget 2018;9:34644-57. DOI PubMed PMC

73. Bartolomé-Izquierdo N, de Yébenes VG, Álvarez-Prado AF, et al. miR-28 regulates the germinal center reaction and blocks tumor growth in preclinical models of non-Hodgkin lymphoma. Blood 2017;129:2408-19. DOI PubMed PMC

74. Anvarnia A, Mohaddes-Gharamaleki F, Asadi M, Akbari M, Yousefi B, Shanehbandi D. Dysregulated microRNAs in colorectal carcinogenesis: new insight to cell survival and apoptosis regulation. J Cell Physiol 2019;234:21683-93. DOI PubMed

75. To KK, Tong CW, Wu M, Cho WC. MicroRNAs in the prognosis and therapy of colorectal cancer: from bench to bedside. World $J$ Gastroenterol 2018;24:2949-73. DOI PubMed PMC

76. Ding J, Zhao Z, Song J, Luo B, Huang L. MiR-223 promotes the doxorubicin resistance of colorectal cancer cells via regulating epithelial-mesenchymal transition by targeting FBXW7. Acta Biochim Biophys Sin (Shanghai) 2018;50:597-604. DOI PubMed

77. Wu QB, Sheng X, Zhang N, Yang MW, Wang F. Role of microRNAs in the resistance of colorectal cancer to chemoradiotherapy. Mol Clin Oncol 2018;8:523-7. DOI PubMed PMC

78. Subramanian S, Lui WO, Lee CH, et al. MicroRNA expression signature of human sarcomas. Oncogene 2008;27:2015-26. DOI PubMed

79. Kelly L, Bryan K, Kim SY, et al; NIH Pediatric and Wild-Type GIST Clinic. Post-transcriptional dysregulation by miRNAs is implicated in the pathogenesis of gastrointestinal stromal tumor [GIST]. PLoS One 2013;8:e64102. DOI PubMed PMC

80. Akçakaya P, Caramuta S, Åhlen J, et al. microRNA expression signatures of gastrointestinal stromal tumours: associations with imatinib resistance and patient outcome. Br J Cancer 2014;111:2091-102. DOI PubMed PMC

81. Khoury S, Tran N. Circulating microRNAs: potential biomarkers for common malignancies. Biomark Med 2015;9:131-51. DOI PubMed

82. Treiber T, Treiber N, Meister G. Regulation of microRNA biogenesis and its crosstalk with other cellular pathways. Nat Rev Mol Cell Biol 2019;20:5-20. DOI PubMed

83. Carter JV, Galbraith NJ, Yang D, Burton JF, Walker SP, Galandiuk S. Blood-based microRNAs as biomarkers for the diagnosis of colorectal cancer: a systematic review and meta-analysis. Br J Cancer 2017;116:762-74. DOI PubMed PMC

84. Germano G, Mauri G, Siravegna G, et al. Parallel evaluation of circulating tumor DNA and circulating tumor cells in metastatic colorectal cancer. Clin Colorectal Cancer 2018;17:80-3. DOI PubMed

85. Liu HN, Liu TT, Wu H, et al. Serum microRNA signatures and metabolomics have high diagnostic value in colorectal cancer using two novel methods. Cancer Sci 2018;109:1185-94. DOI PubMed PMC

86. Liu HN, Wu H, Tseng YJ, et al. Serum microRNA signatures and metabolomics have high diagnostic value in gastric cancer. $B M C$ Cancer 2018;18:415. DOI PubMed PMC

87. Toiyama Y, Okugawa Y, Fleshman J, Richard Boland C, Goel A. MicroRNAs as potential liquid biopsy biomarkers in colorectal cancer: a systematic review. Biochim Biophys Acta Rev Cancer 2018;1870:274-82. DOI PubMed PMC

88. Du B, Wu D, Yang X, et al. The expression and significance of microRNA in different stages of colorectal cancer. Medicine (Baltimore) 2018;97:e9635. DOI PubMed PMC

89. Vychytilova-Faltejskova P, Radova L, Sachlova M, et al. Serum-based microRNA signatures in early diagnosis and prognosis prediction of colon cancer. Carcinogenesis 2016;37:941-50. DOI PubMed

90. Yang J, Ma D, Fesler A, et al. Expression analysis of microRNA as prognostic biomarkers in colorectal cancer. Oncotarget 2017;8:52403-12. DOI PubMed PMC

91. Ogata-Kawata H, Izumiya M, Kurioka D, et al. Circulating exosomal microRNAs as biomarkers of colon cancer. PLoS One 2014;9:e92921. DOI PubMed PMC

92. Jacob H, Stanisavljevic L, Storli KE, Hestetun KE, Dahl O, Myklebust MP. Identification of a sixteen-microRNA signature as 
prognostic biomarker for stage II and III colon cancer. Oncotarget 2017;8:87837-47. DOI PubMed PMC

93. Coebergh van den Braak RRJ, Sieuwerts AM, Lalmahomed ZS, et al; MATCH study group*. Confirmation of a metastasis-specific microRNA signature in primary colon cancer. Sci Rep 2018;8:5242. DOI PubMed PMC

94. Jacob H, Stanisavljevic L, Storli KE, Hestetun KE, Dahl O, Myklebust MP. A four-microRNA classifier as a novel prognostic marker for tumor recurrence in stage II colon cancer. Sci Rep 2018;8:6157. DOI PubMed PMC

95. Zhu M, Huang Z, Zhu D, et al. A panel of microRNA signature in serum for colorectal cancer diagnosis. Oncotarget 2017;8:1708191. DOI PubMed PMC

96. Zhang H, Zhu M, Shan X, et al. A panel of seven-miRNA signature in plasma as potential biomarker for colorectal cancer diagnosis. Gene 2019;687:246-54. DOI PubMed

97. Wikberg ML, Myte R, Palmqvist R, van Guelpen B, Ljuslinder I. Plasma miRNA can detect colorectal cancer, but how early? Cancer Med 2018;7:1697-705. DOI PubMed PMC

98. Karimi N, Ali Hosseinpour Feizi M, Safaralizadeh R, et al. Serum overexpression of miR-301a and miR-23a in patients with colorectal cancer. J Chin Med Assoc 2019;82:215-20. DOI PubMed

99. Liu X, Xu X, Pan B, et al. Circulating miR-1290 and miR-320d as novel diagnostic biomarkers of human colorectal cancer. $J$ Cancer 2019;10:43-50. DOI PubMed PMC

100. Yang Q, Wang S, Huang J, Xia C, Jin H, Fan Y. Serum miR-20a and miR-486 are potential biomarkers for discriminating colorectal neoplasia: a pilot study. $J$ Cancer Res Ther 2018;14:1572-7. DOI PubMed

101. Chang PY, Chen CC, Chang YS, et al. MicroRNA-223 and microRNA-92a in stool and plasma samples act as complementary biomarkers to increase colorectal cancer detection. Oncotarget 2016;7:10663-75. DOI PubMed PMC

102. Zhou X, Wen W, Shan X, et al. A six-microRNA panel in plasma was identified as a potential biomarker for lung adenocarcinoma diagnosis. Oncotarget 2017;8:6513-25. DOI PubMed PMC

103. Monzo M, Santasusagna S, Moreno I, et al. Exosomal microRNAs isolated from plasma of mesenteric veins linked to liver metastases in resected patients with colon cancer. Oncotarget 2017;8:30859-69. DOI PubMed PMC

104. Montagnana M, Benati M, Danese E, et al. Plasma expression levels of circulating miR-21 are not useful for diagnosing and monitoring colorectal cancer. Clin Lab 2016;62:967-70. DOI

105. Micallef I, Baron B. The mechanistic roles of ncRNAs in promoting and supporting chemoresistance of colorectal cancer. Noncoding RNA 2021;7:24. DOI PubMed PMC

106. Sasaki M, Ishikawa T, Ishiguro M, et al. The effectiveness of plasma miR-33a-5p as a predictive biomarker for the efficacy of colorectal cancer chemotherapy. Oncol Lett 2021;21:489. DOI PubMed PMC

107. Li J, Mo R, Zheng L. MicroRNA-490-3p inhibits migration and chemoresistance of colorectal cancer cells via targeting TNKS2. World J Surg Oncol 2021;19:117. DOI PubMed PMC

108. Mou Y, He N, Su M, et al. MiR-1254 and MEGF6 regulates oxaliplatin resistance in human colorectal cancer cells. Am J Transl Res 2021;13:183-96. PubMed PMC 